\title{
Polymer tensiometers with ceramic cones: direct observations of matric pressures in drying soils
}

\author{
M. J. van der Ploeg ${ }^{1}$, H. P. A. Gooren ${ }^{1}$, G. Bakker ${ }^{2}$, C. W. Hoogendam ${ }^{3}$, C. Huiskes ${ }^{4}$, L. K. Koopal ${ }^{3}$, H. Kruidhof ${ }^{4}$, \\ and G. H. de Rooij ${ }^{1,5}$ \\ ${ }^{1}$ Dept. Environmental Sciences, Soil Physics, Ecohydrology and Groundwater Management Group, Wageningen University, \\ The Netherlands \\ ${ }^{2}$ ALTERRA, Wageningen, The Netherlands \\ ${ }^{3}$ Laboratory for Physical Chemistry and Colloid Science, Wageningen University, The Netherlands \\ ${ }^{4}$ Faculty of Science and Technology, Twente University, The Netherlands \\ ${ }^{5}$ Dept. Soil Physics, Helmholtz Centre for Environmental Research - UFZ, Halle, Germany
}

Received: 13 May 2009 - Published in Hydrol. Earth Syst. Sci. Discuss.: 16 June 2009

Revised: 31 July 2010 - Accepted: 18 August 2010 - Published: 4 October 2010

\begin{abstract}
Measuring soil water potentials is crucial to characterize vadose zone processes. Conventional tensiometers only measure until approximately $-0.09 \mathrm{MPa}$, and indirect methods may suffer from the non-uniqueness in the relationship between matric potential and measured properties. Recently developed polymer tensiometers (POTs) are able to directly measure soil matric potentials until the theoretical wilting point $(-1.6 \mathrm{MPa})$. By minimizing the volume of polymer solution inside the POT while maximizing the ceramic area in contact with that polymer solution, response times drop to acceptable ranges for laboratory and field conditions. Contact with the soil is drastically improved with the use of coneshaped solid ceramics instead of flat ceramics. The comparison between measured potentials by polymer tensiometers and indirectly obtained potentials with time domain reflectometry highlights the risk of using the latter method at low water contents. By combining POT and time domain reflectometry readings in situ moisture retention curves can be measured over the range permitted by the measurement range of both POT and time domain reflectometry.
\end{abstract}

\section{Introduction}

Measurement of the soil water matric potential $\left(\psi_{m}\right)$ is important to characterize and monitor processes in vadose zone hydrology, such as plant growth, crop production, aquifer

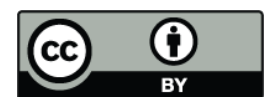

Correspondence to: M. J. van der Ploeg (martine.vanderploeg@wur.nl) recharge, and leaching below buried waste disposal sites (Young and Sisson, 2002). Tensiometers are widely used instruments to monitor $\psi_{m}$, and have been used for almost 100 years (Or, 2001; Young and Sisson, 2002). All tensiometers consist of three elements: a ceramic that is in contact with the soil, a water reservoir in equilibrium with the soil water, and a pressure measurement device that measures this equilibrium accordingly. Unfortunately, water-filled tensiometers are only able to measure $\psi_{m}$ above approximately $-0.09 \mathrm{MPa}$, and soil physical experimental research is hampered by this very limited measurement range (We will consistently deploy the pressure equivalent of the matric potential).

Reece (1996) stated that field psychrometers have a measurement range between -0.5 and $-5 \mathrm{MPa}$ when used with sensitive instrumentation, and without temperature gradients, but did not give additional quantitative data. Agus and Schanz (2005) on the other hand, note that thermocouple psychrometers have a slow response and are subject to significant measurement errors above $-1.0 \mathrm{MPa}$. Measurements of $\psi_{m}$ between -0.09 and $-0.5 \mathrm{MPa}$ can be done by filter paper, electrical resistance, inference from soil moisture content and soil moisture retention curve, and heat dissipation methods (e.g. Noborio et al., 1999; Andraski and Scanlon, 2002; Agus and Schanz, 2005). These methods are not derived from thermodynamic principles, but rely on calibrating sensor properties against known $\psi_{m}$ (Campbell and Gee, 1986). Difficulties arise from the non-uniqueness in the relationship between $\psi_{m}$ and measured properties, as the measured properties also depend on other variables (for example temperature) (Campbell, 1988).

Published by Copernicus Publications on behalf of the European Geosciences Union. 


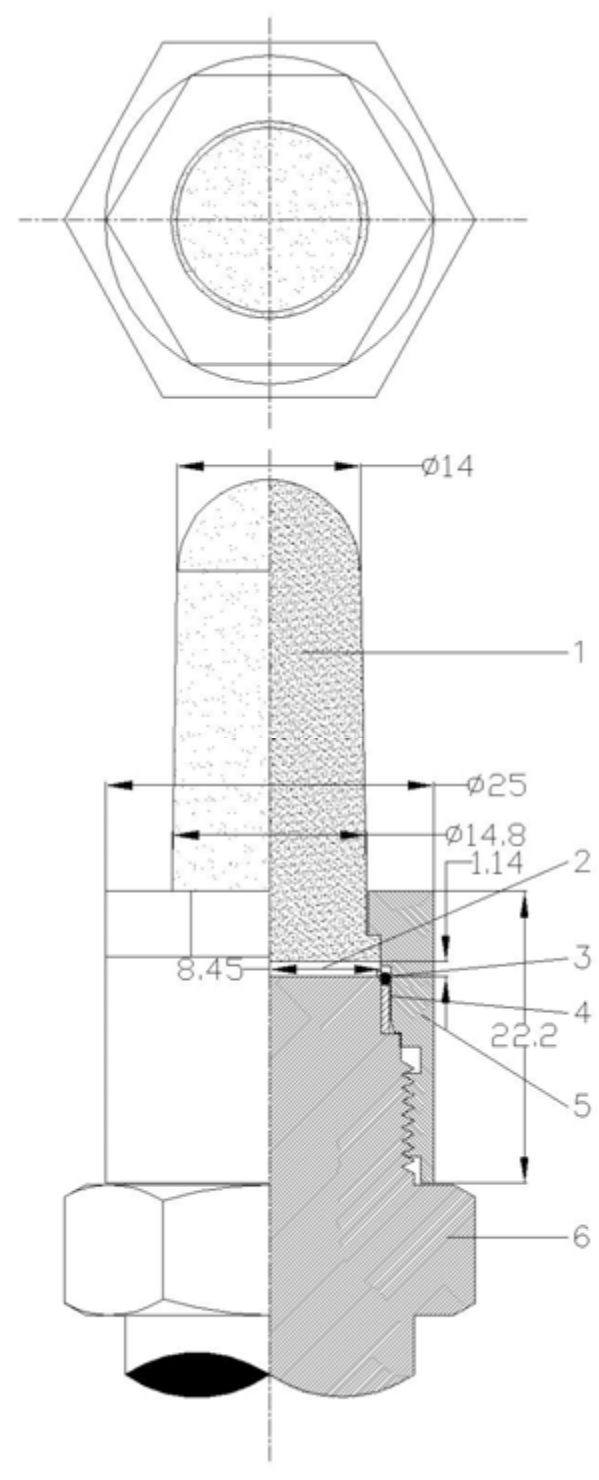

Fig. 1. Polymer tensiometer (POT) design with cone-shaped ceramic containing (1) an $\alpha-\mathrm{Al}_{2} \mathrm{O}_{3}$ support layer with a $\gamma-\mathrm{Al}_{2} \mathrm{O}_{3}$ membrane at the base of the cone, (2) polymer chamber, (3) rubber O-ring, (4) stainless steel ring, (5) stainless steel mounting ring, and (6) a pressure transducer. Various arrows indicate lengths in $\mathrm{mm}$ of components of POT ( $\emptyset$ is diameter).

Attempts have been made to circumvent cavitation of tensiometers and to extend their measurement range. Tamari et al. (1993) used microtensiometers that could measure until approximately $-0.14 \mathrm{MPa}$ for short time periods. $\mathrm{Nu}-$ cleation particles were removed by purging the tensiometers extensively with demineralized water, and this created the possibility of having a metastable state of the liquid. Miller and Salehzadeh (1993) used a stripper to remove dissolved air from the tensiometer's water reservoir, and could thus reach $-0.18 \mathrm{MPa}$. Combining degassed water that was free of nucleation particles with hydrophilic, polished materials Schindler et al. (2010) reached values down to $-0.44 \mathrm{MPa}$. For geotechnical applications Ridley and Burland (1993, 1999) constructed a tensiometer that measured $\psi_{m}$ down to $-1.5 \mathrm{MPa}$, unfortunately the instrument worked for a few hours or less. This tensiometer, later studied by Guan and Fredlund (1997) and Tarantino and Mongiovì (2001), required a $24 \mathrm{~h}$ pre-hydration phase in a high pressure chamber, at 4.0 MPa, to dissolve air bubbles, and stopped working as soon as cavitation occurred. The tensiometer can only be used in the laboratory due to the elaborate preparation prior to use.

Peck and Rabbidge $(1966,1969)$ were the first to use a polymer solution instead of water. The osmotic potential $(\pi)$ of a hydrophilic polymer causes a build-up of pressure when the polymer is exposed to free water through a membrane permeable to water but not to the polymer. Using the subsequent drop in $\pi$ as a measure for the actual $\psi_{m}$ in the soil, Peck and Rabbidge (1969) were able to measure down to $-1.5 \mathrm{MPa}$. Their instrument, later studied by Bocking and Fredlund (1979), suffered from gradual loss of pressure, unkown zero drift, temperature effects and slow equilibration times. Progress on polymer filled tensiometers was not made until a ceramic was used that greatly reduced polymer leakage (Biesheuvel et al., 1999). Bakker et al. (2007) presented a polymer filled tensiometer that worked properly beyond wilting point, and found an empirical relation to predict the remaining loss in pressure caused by diffusion of some smaller-sized polymers through the membrane (Caulfield et al., 2003). It was also shown that by reducing the volume of the polymer solution, the polymer tensiometer's (POT) response time decreased. Bakker et al. (2007) used flat ceramics, which provided a challenge to ensure good contact between the soil and a POT.

In this paper we describe POTs that used ceramic cones instead of flat ceramics. The cones had an air entry value below $-1.75 \mathrm{MPa}$, and thus they remained equally conductive until the theoretical wilting point of $-1.6 \mathrm{MPa}$. The function of the cones is to transfer the $\psi_{m}$ from the soil water to the polymer solution with minimum water displacement. We evaluated their performance in soil by comparing the recorded $\psi_{m}$ by those derived from time domain reflectometry (TDR). The soil moisture content $\left(\theta_{\mathrm{TDR}}\right.$; note that a subscript for $\theta$ indicates the method used to determine its value) readings were converted to $\psi_{m}$ using the soil moisture retention curve $\left(\theta_{\operatorname{GRAV}}\left(\psi_{m}\right)\right)$. TDR has gained widespread acceptance as a standard method to measure $\theta$ (e.g. Ferré and Topp, 2002), and has served as a method to develop sensors that infer $\psi_{m}$ instantly (e.g. Or and Wraith 1999).

The objective of this paper is to present POT designs that minimize the volume of the polymer solution while maximizing the ceramic area in contact with the polymer solution, and that provides a solution towards contact problems between the ceramic and the soil. We thoroughly tested the designs in two soil types, and compared the observations with TDR- 
Table 1. Properties of polymer tensiometers (POTs) used in the evaporation boxes (EB).

\begin{tabular}{llllllll}
\hline POT design & EB & $\begin{array}{l}\text { Placement } \\
\text { in EB* }\end{array}$ & $\begin{array}{l}\text { Chamber depth } \\
\left(10^{-3} \mathrm{~m}\right)\end{array}$ & $\begin{array}{l}\text { Polymer } \\
\text { type }\end{array}$ & $\begin{array}{l}\text { Polymer } \\
\text { amount }(\mathrm{g})\end{array}$ & $\begin{array}{l}\text { Ceramic area in contact } \\
\text { with polymer solution } \\
\left(10^{-3} \mathrm{~m}^{2}\right)\end{array}$ & $\begin{array}{l}\text { Ceramic surface in } \\
\text { contact with soil } \\
\left(10^{-3} \mathrm{~m}^{2}\right)\end{array}$ \\
\hline 1A & 1 & BR & 2.5 & Praestol 2500 & 0.275 & 0.167 & 1.45 \\
1B & 2 & BL & 2.5 & Dextran 500 & 0.229 & 0.167 & 1.45 \\
2 & 1 & BL & 1.2 & Praestol 2500 & 0.087 & 0.224 & 1.76 \\
3A & 1 & TR & 1.1 & Praestol 2500 & 0.124 & 0.224 & 1.76 \\
3B & $1 ; 2$ & TL & 1.1 & Praestol 2500 & 0.100 & 0.224 & 1.76 \\
4A & 2 & TR & 1.1 & Praestol 2500 & 0.067 & 0.260 & 1.74 \\
4B & 2 & BR & 1.1 & Praestol 2500 & 0.090 & 0.260 & 1.74 \\
\hline
\end{tabular}

${ }^{*}$ Top left (TL), Top right (TR), Bottom left (BL), Bottom right (BR).

Table 2. Properties of the polymers used in the polymer tensiometers.

\begin{tabular}{|c|c|c|c|c|}
\hline $\begin{array}{l}\text { Polymer } \\
\text { (trade name) }\end{array}$ & $\begin{array}{l}\text { Polymer } \\
\text { type }\end{array}$ & $\begin{array}{l}\text { Average molar } \\
\text { mass }\left(\mathrm{kg} \mathrm{mol}^{-1}\right)\end{array}$ & $\begin{array}{l}\text { Percentage of } \\
\text { anionic groups }\end{array}$ & $\begin{array}{l}\text { Phase separation when } \\
\text { dissolved in water at }\end{array}$ \\
\hline Praestol 2500 & Polyacrylamide & 2500 & $1^{\dagger}$ & $<-35^{\circ} \mathrm{C}^{\ddagger}$ \\
\hline Dextran 500 & Polysaccharide & 500 & 0 & $<0^{\circ} \mathrm{C},>50^{\circ} \mathrm{C}$ \\
\hline
\end{tabular}

$\dagger$ Davidson (1980, p. 16-2), ${ }^{\dagger}$ Molyneux (1983, p. 11 Fig. 1).

derived values and the measurement range of water-filled tensiometers. Furthermore, we investigated the possibility of combining POT and TDR data to derive in situ moisture retention curves $\left(\theta_{\operatorname{TDR}}\left(\psi_{m}\right)\right)$.

\section{Materials and methods}

\subsection{Design and operational procedures}

We used a design (Table 1) that incorporated a solid cylindrical $\alpha-\mathrm{Al}_{2} \mathrm{O}_{3}$ ceramic instead of a flat ceramic (Fig. 1) (Peck and Rabbidge 1966, 1969; Biesheuvel et al., 1999; Bakker et al., 2007), to ensure good contact with the soil. A $2 \mu \mathrm{m}$ thick $\gamma-\mathrm{Al}_{2} \mathrm{O}_{3}$ ceramic membrane purposed to prevent large polymer leakage (Alami-Younssi et al., 1995; Bakker et al., 2007, De Vos and Verweij, 1998) was applied to the base of the cones. The ceramic cone is the substrate carrier for the $\gamma-\mathrm{Al}_{2} \mathrm{O}_{3}$ membrane, and the pores are $160 \mathrm{~nm}$ and $2.5 \mathrm{~nm}$ respectively. The cone's and membrane's air entry value equals -1.83 and $-117 \mathrm{MPa}$ respectively (water surface tension $0.073 \mathrm{~N} \mathrm{~m}^{-1}$ and water density $998 \mathrm{~kg} \mathrm{~m}^{-3}$ at $20^{\circ} \mathrm{C}$ ). The construction details were described by Bakker et al. (2007), with the exception that their $0.2 \mathrm{~mm}$ synthetic ring was replaced by a rubber O-ring at the side of the pressure transducer. This modification eliminated undesired forces to the top of the transducer, which might lead to deformation and malfunctioning of the transducer. The pressure transducer had a range of -0.175 to $2.201 \mathrm{MPa}$, and an accuracy of $2.38 \times 10^{-3} \mathrm{MPa}(0.1 \%$ of the full scale $)$, and includes a temperature sensor $\left(0-40^{\circ} \mathrm{C}\right.$, accuracy $\left.0.01^{\circ} \mathrm{C}\right)$.

We used four variants of the design, in which the surface area of the ceramic in contact with the soil and the surface area in contact with the polymer chamber were varied, i.e. by adjusting the length and diameter of the ceramic. This resulted in different polymer chamber heights (Table 1). The various POT designs (identified by a number in Table 1) had repercussions for the level of skill required to manufacture the POT, and also affected its behavior. The polymer chamber height (Table 1) ranged from 2.5 to $1.1 \mathrm{~mm}$, which was 2 to 4 times smaller than described by Bakker et al. (2007). We used seven POTs filled with Praestol 2500 and one with Dextran 500 (see Table 2 for specific properties). After filling, the POTs were placed in a temperature controlled water bath filled with demineralized water for at least 28 days at $25^{\circ} \mathrm{C} \pm 0.01^{\circ} \mathrm{C}$ to allow the polymer to saturate. Long-term behavior and pressure-temperature relationships as described by Bakker et al. (2007) were determined before using the POTs in soil. From the measurements to determine the pressure-temperature relationships we could also determine temperature response times of the various POT 

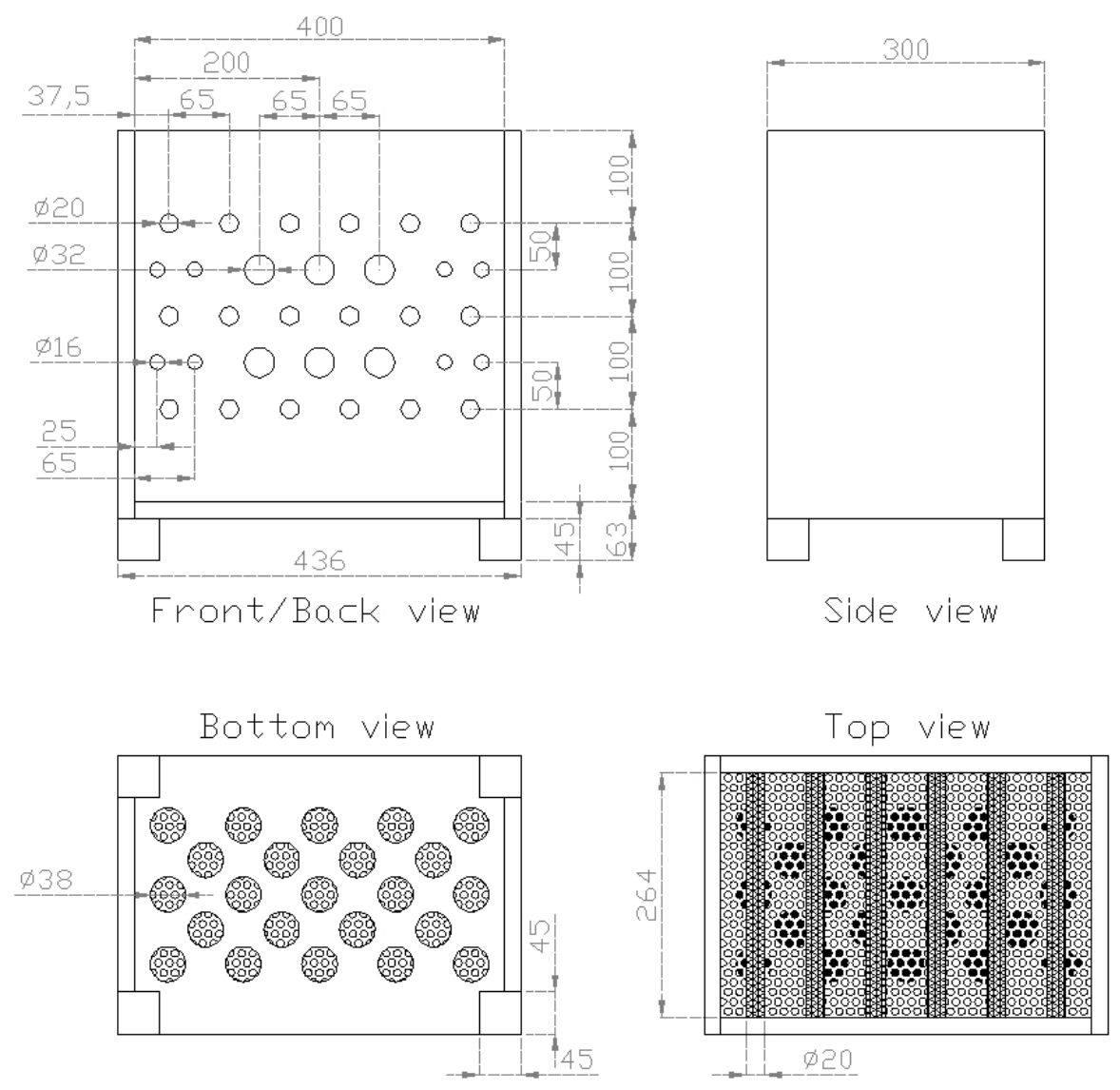

Fig. 2. Design of the box used for the evaporation experiment. Ports of $20 \mathrm{~mm}$ held wall to wall perforated tubes that were covered with cloth. Polymer tensiometers (POTs) were placed through the $32 \mathrm{~mm}$ front ports, top-left, top-right, bottom left, bottom right. Time domain reflectometry wave guides (TDR probes) were placed at the back ports, one opposite of each POT. Conventional tensiometers (CTs) were placed at the front and back top middle and bottom middle $32 \mathrm{~mm}$ ports. Ports of $16 \mathrm{~mm}$ facilitated soil sampling to verify the bulk electrical permittivity-volumetric soil moisture relationship during the experiment. All measures in $\mathrm{mm}$.

designs (Bakker et al., 2007). Pressure change caused by external pressure variations were instantaneous regardless of POT design, and are therefore not further discussed.

\subsection{Evaporation experiments}

To determine the $\psi_{m}$ with POTs, the $\pi$ of each individual POT in the water bath is required as a reference. By using the subsequent drop in pressure the positive $\pi$ inside the POT can be related to the negative $\psi_{m}$ in the soil. For the evaporation experiment this reference pressure was determined by averaging pressure measurements over $24 \mathrm{~h}$ before the instruments were taken out of the water bath, and installed in soil. We ignored the hydrostatic pressure component, since the immersion depth $(<0.2 \mathrm{~m})$ produced a pressure three orders of magnitude smaller than $\pi$ inside the POT.
We filled two evaporation boxes (EB) of $0.40 \times 0.30 \times 0.40 \mathrm{~mL} \times \mathrm{W} \times \mathrm{H}$ (Fig. 2), one with sand ( $97.6 \%$ sand, $1.6 \%$ silt, $0.8 \%$ clay; EB1), and the other with loam ( $42.8 \%$ sand, $38.8 \%$ silt, $18.4 \%$ clay; EB2). Both materials were sieved at $2 \mathrm{~mm}$, and uniformly pre-wetted. We added soil in $5 \mathrm{~cm}$ layers, tamped them, and raked the upper $2 \mathrm{~cm}$ before adding a new layer. The containers were equipped with a perforated bottom that was covered by a steel grid and a cloth, and with wall-to-wall perforated PVC tubes (outer diameter of $20 \mathrm{~mm}$ ), also covered with cloth. The perforations facilitated fast and uniform drying of the soil. To enhance evaporation, the air humidity in the laboratory was kept low by using an air dryer.

Each EB was equipped with 4 POTs (See Table 1 for specific properties), 4 TDR-probes (Minitrase, Soilmoisture Equipment) and 4 conventional, water-filled tensiometers (CTs, Rhizo Instruments) that were installed while filling the boxes (Fig. 2). We used 3-rod TDRs with $8 \mathrm{~cm}$ long, $0.32 \mathrm{~cm}$ diameter rods spaced at $1.4 \mathrm{~cm}$, which gives an approximate 
Table 3. Temperature and rewetting response times for the various POT designs.

\begin{tabular}{lllllll}
\hline & \multicolumn{4}{c}{ Temperature response time in hours averaged } & \multicolumn{2}{c}{$\begin{array}{c}\text { Rewetting response } \\
\text { times in days }\end{array}$} \\
POT design & $5^{\circ} \mathrm{C}$ drop & $2.5^{\circ} \mathrm{C}$ drop & $5^{\circ} \mathrm{C}$ rise & $2.5^{\circ} \mathrm{C}$ rise & In evaporation box 1 & In a water bath \\
\hline 1A & $2.76(6)$ & - & $2.54(6)$ & - & 3.98 & - \\
1B & - & $0.576(2)$ & - & $1.13(2)$ & - & 0.668 \\
2 & $0.576(6)$ & - & $0.336(6)$ & - & 0.503 & - \\
3A & $0.816(6)$ & - & $0.672(6)$ & - & 0.615 & - \\
3B & $0.816(6)$ & $0.792(2)$ & $0.480(6)$ & $0.480(2)$ & 0.600 & 0.140 \\
4A & - & $0.240(2)$ & - & $0.168(2)$ & - & 0.203 \\
4B & - & $0.336(2)$ & - & $0.288(2)$ & - & 0.564 \\
\hline
\end{tabular}

$\dagger$ See Bakker et al. (2007) for details, $¥$ Response time defined as the period between the onset of rewetting and the time at which the observed pressure change equaled the measurement noise.

measurement volume of $250 \mathrm{~cm}^{3}$ (Ferré et al., 1998; Huisman et al., 2001). The POTs and TDRs were placed opposite to each other; the CTs were placed in between. The CTs contained a gas stripper that was connected to a vacuum pump (Miller and Salehzadeh, 1993) to prevent formation of air bubbles inside the instrument. During the evaporation experiment, the POTs, TDRs and CTs had a measurement interval of $10 \mathrm{~min}$. EB1 (sand) was gradually saturated from the bottom by placing the box in a larger, water tight encasing, and adding non-chlorinated tap water at $1 \mathrm{~cm} \mathrm{~h}^{-1}$ (with a maximum of $8 \mathrm{~cm} \mathrm{~d}^{-1}$ ) for seven days, then leaving the set-up water-logged for two days before opening an outlet in the outer casing to drain the sand. EB2 (loam) was similarly saturated at a rate of $2 \mathrm{~cm} \mathrm{~h}^{-1}$ (with a maximum of $12 \mathrm{~cm} \mathrm{~d}^{-1}$ ) for four days, and drained six days later. Upon drainage the soil volume in EB2 reduced $2.5 \%$ in the vertical direction. The influence of salts of the tap water and in the original soil solution on the osmotic potential inside the POTs was assumed negligible.

After some time the drying process slowed down in EB1. We therefore placed a small ventilator in front of the box facing the outlets of the PVC tubes 42 days after drying commenced. A similar ventilator was used for EB2 during the entire experiment. Soil samples of $20 \mathrm{~cm}^{3}$ were taken during the experiment to establish a soil specific relation between the volumetric moisture content $(\theta)$ and measured dielectric permittivity of the TDRs. At the end of the experiment EB1 was moistened from below by controlling the water level at the bottom of the container for 7 days to verify the response of the POTs, then gradually saturated in 3 days. Since some soil volume reduction was observed in EB2, it was not rewetted to prevent density changes due to possible soil swelling, and to observe cracks as a result of shrinkage. No cracks were observed, which suggest the reduction in soil volume was a results of soil setting during drainage. For EB2 the POTs were taken out of the soil, and placed back into the temperature controlled water bath. POT responses were recorded before, during and after the transfer from the soil to the water bath. After the evaporation experiments, pressuretemperature relations were again determined for all POTs, to monitor possible changes in the chemical properties of the polymer solutions.

We obtained $100 \mathrm{~cm}^{3}$ undisturbed soil cores from both boxes to determine the $\theta_{\mathrm{GRAV}}\left(\psi_{m}\right)$-curve $(N=16$ for EB1; $N=14$ for EB2) and the bulk density ( $N=16$ for EB $1 ; N=18$ for EB2) (Dirksen, 1999; Grossman and Reinsch, 2002). For $\psi_{m}$ between $-2 \times 10^{-4}$ and $-1 \times 10^{-2} \mathrm{MPa}$, we placed the soil cores in a hanging water column set-up (Romano et al., 2002), and related $\theta_{\mathrm{GRAV}}$ to $\psi_{m}$ in the center of the sample (sample height $5 \mathrm{~cm}$ ). For $\psi_{m}<-1 \times 10^{-2} \mathrm{MPa}$ we used the pressure plate method with $0.5 \mathrm{~cm}$ high samples filled with disturbed saturated soil (Campbell, 1988; Dirksen, 1999; Dane and Hopmans, 2002). The obtained $\theta_{\mathrm{GRAV}}$ from these measurements were converted to volumetric $\theta$, by using a constant density for water $\left(1000 \mathrm{~kg} \mathrm{~m}^{-3}\right)$, and the bulk density from each soil sample previously used in the hanging water column set-up (Topp and Ferré, 2002).

To determine in situ retention curves, each POT was paired with an opposite TDR (Fig. 2). Data were paired according to measurement time. Differences between the internal clocks of the POTs and TDRs were negligible. We assumed that for each TDR-POT pair, instrument location in the tank and the different measurement volumes of both instruments did not affect the shape of the retention curve. To fit the gravimetric measurements from soil cores we used a linear interpolation for EB1 due to the nature of that retention curve, and the van Genuchten equation for EB2 (1980).

Because we initially saturated the soil, the resulting moisture retention curve is the main drainage curve (Dane and Hopmans, 2002). This retention curve was subsequently 


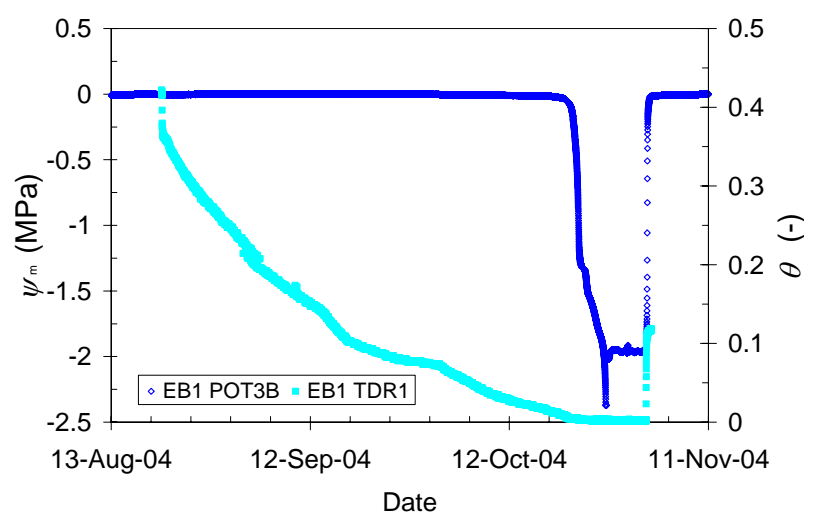

(a)

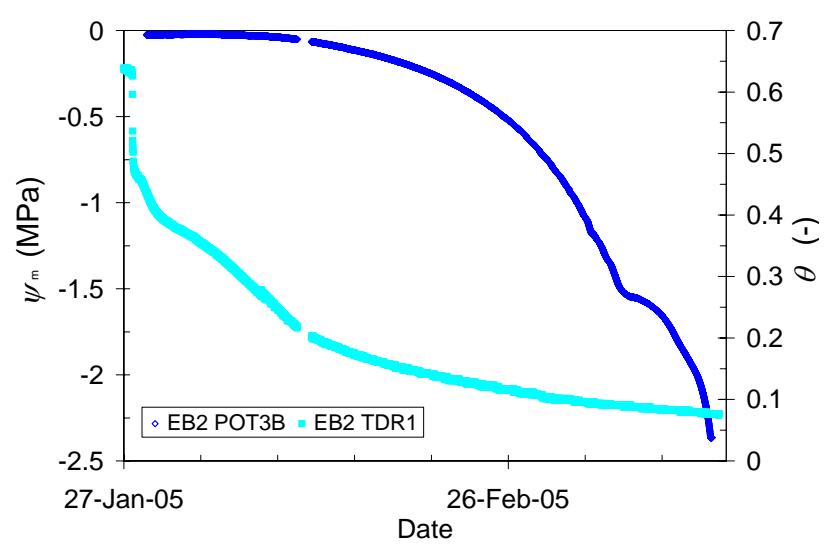

(b)

Fig. 3. Development of the matric potential $\psi_{m}$ of polymer tensiometer 3B (POT3B) and moisture content $\theta$ (TDR1) in time for evaporation box EB1 (a) and EB2 (b).

used to convert $\theta_{\mathrm{TDR}}$ observations to $\psi_{m}$ to compare the POT readings independently.

\section{Results}

\subsection{Temperature response times}

Temperature response times for the various POT designs are given in Table 3. The temperature response times include the time it took the water bath to heat up (in case of a temperature rise) and cool down (in case of a temperature drop). For $5^{\circ} \mathrm{C}$ increments, and depending on the temperature in the laboratory, a temperature drop could take up to $0.408 \mathrm{~h}$ and a temperature rise up to $0.166 \mathrm{~h}$. For $2.5^{\circ} \mathrm{C}$ increments we could decrease cooling time to $0.166 \mathrm{~h}$, and heating time to $0.084 \mathrm{~h}$.

Smaller polymer chamber heights resulted in shorter response times. An exception is POT1B that had, despite its polymer chamber height of $2.5 \times 10^{-3} \mathrm{~m}$, a comparable response time with POT3B with a polymer chamber height of

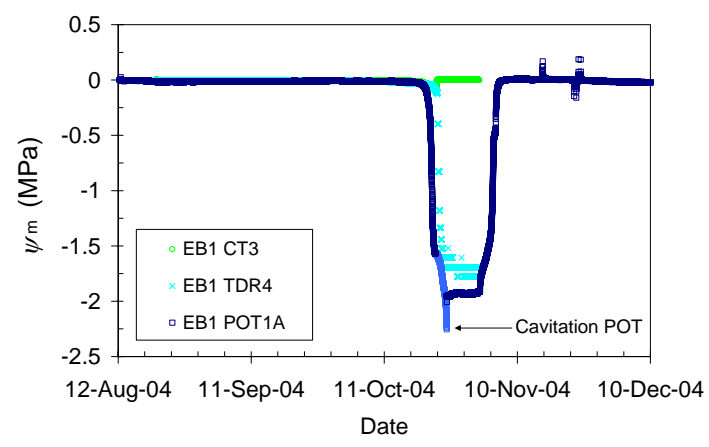

(a)

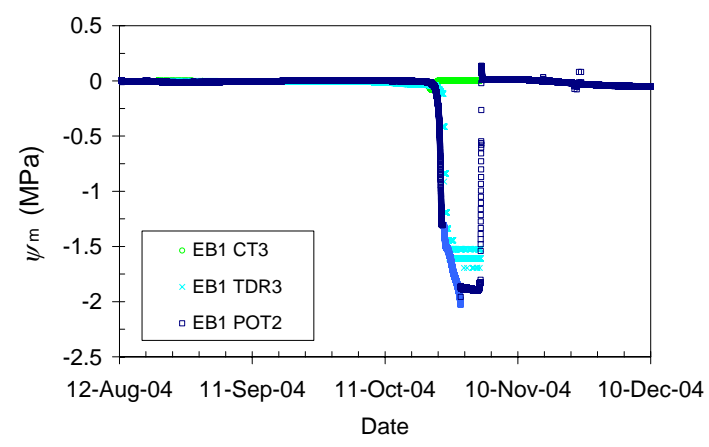

(b)

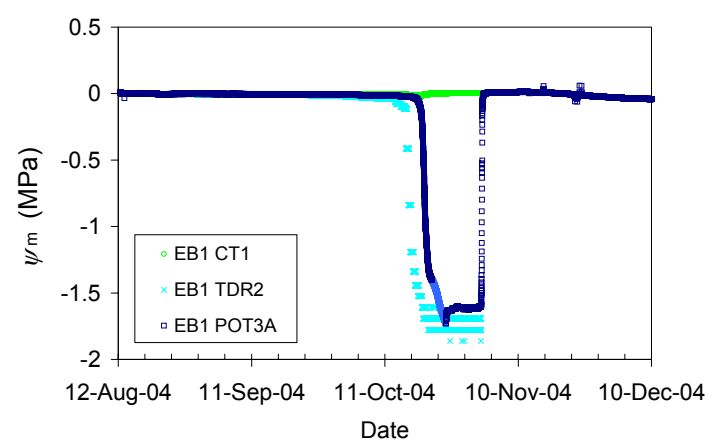

(c)

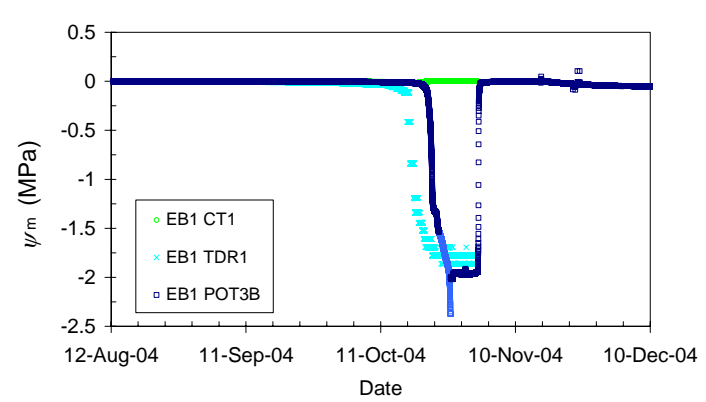

(d)

Fig. 4. Development of the matric potential $\psi_{m}$ in time measured by polymer tensiometers (POT), time domain reflectometry probes (TDR) and water-filled tensiometers (CT) in evaporation container 1 (EB1) that was filled with sand. Each sub-figure shows a POTTDR pair installed opposite to one another, and the nearest CT. 
$1.1 \times 10^{-3} \mathrm{~m}$. In POT1B the response time for the $2.5^{\circ} \mathrm{C}$ drop was shorter than for the $2.5^{\circ} \mathrm{C}$ rise, whereas all other POTs showed the opposite. This deviating behavior can probably be attributed to the Dextran used in this POT.

POT design 3 and 4 (Table 1) show that a larger ceramic area in contact with the polymer solution shortened the temperature response time. Finally, the amount of polymer inside the polymer chamber had an effect on the temperature response times. This effect could be observed in POT2, which has a larger polymer chamber height than POT3A and POT3B, but contained less polymer, and consequently had shorter response times. Similarly POT $4 \mathrm{~A}$ had shorter response times than POT4B, even though the chamber depth and the ceramic area in contact with the polymer solution were equal.

\subsection{The soil drying process}

The initial $\theta_{\mathrm{TDR}}$ in $\mathrm{EB} 2$ was higher compared to EB1; this is probably an effect of soil repacking (dry bulk density of EB1 $1504 \mathrm{~kg} \mathrm{~m}^{-3}(N=16)$; of EB2 $\left.1366 \mathrm{~kg} \mathrm{~m}^{-3}(N=18)\right)$. Average reduction in $\theta_{\mathrm{TDR}}$ per day was 0.0067 for $\mathrm{EB} 1$ and 0.012 for EB2; the latter was probably higher due to the use of the ventilator throughout the experiment. Average soil temperatures were also slightly higher in $\mathrm{EB} 2\left(25.9^{\circ} \mathrm{C}\right)$ than in $\mathrm{EB} 1$ $\left(24.7^{\circ} \mathrm{C}\right)$.

Figure 3 shows the development of the $\psi_{m}$ and the $\theta_{\text {TDR }}$ in time of EB1 and EB2. POT3B in EB1 showed a sudden drop in pressure after 21 October 2004, whereas the same POT3B showed a much more gradual drop in EB2. These pressure responses are consistent with the typical retention curves of sand (EB1) and loam (EB2). The TDR measurements showed a fast decrease of $\theta_{\mathrm{TDR}}$ by drainage of the saturated soil, and a gradual decrease of $\theta_{\mathrm{TDR}}$ as a result of evaporation. In EB1 the placement of the small ventilator at 1 October 2004 can be seen in the slope of $\theta_{\mathrm{TDR}}$ around that date. We do not know the reason of the slightly erratic behavior around 8 September 2004.

\subsection{Performance of POTs, TDRs, and CTs}

Moisture content measurements $\left(\theta_{\mathrm{TDR}}\right)$ were converted to $\psi_{m}$ by means of the independently determined moisture retention curve $\theta_{\mathrm{GRAV}}\left(\psi_{m}\right)$ (gravimetric measurements on soil cores). Figure 4 illustrates the measurement range of the POTs, together with converted $\theta_{\text {TDR }}$ measurements from the TDR opposite of each POT, and with potential measurements from the CTs in close vicinity of the POTs for EB1 (See Fig. 2). Figure 5 shows a close-up of Fig. 4, within the measurement range of the CT. The resolution of the POTs explains the rather noisy behavior in Fig. 5, compared to the smooth decrease in pressure observed by the CTs. The increase in pressure observed by the POTs in Fig. 5a, b and $d$ can probably be attributed to the concentration of the soil solution, which increases as a result of evaporation. We do not

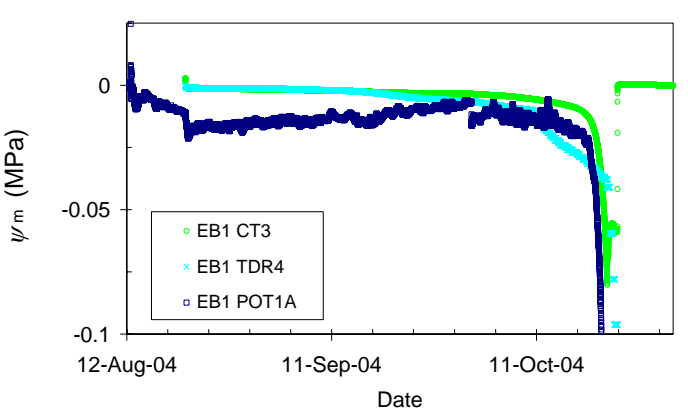

(a)

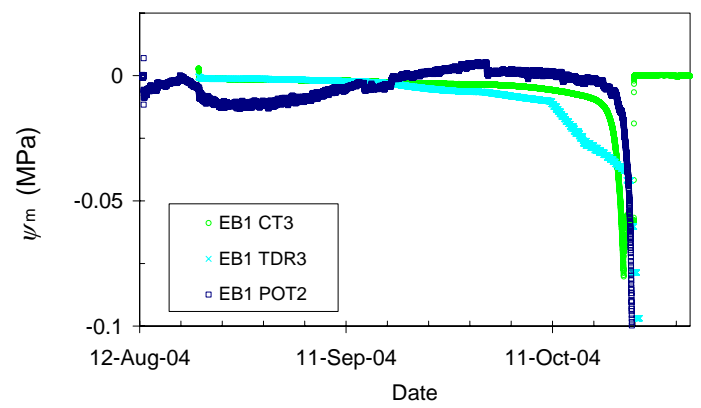

(b)

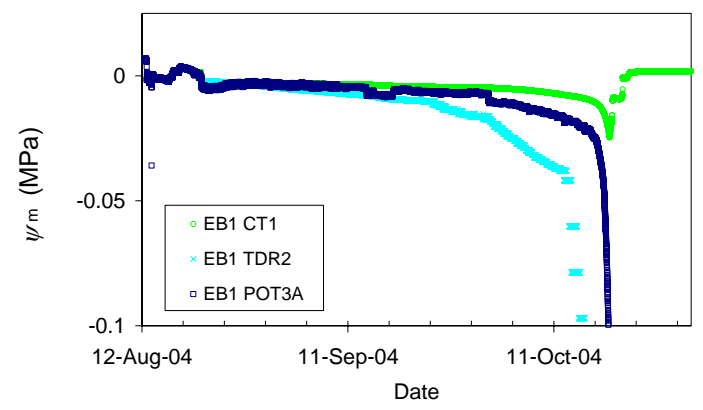

(c)

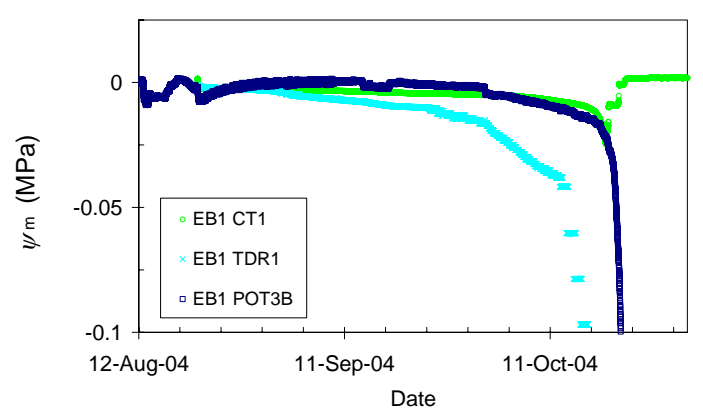

(d)

Fig. 5. Development of the matric potential $\psi_{m}$ in time (detail of Fig. 4) measured by polymer tensiometers (POT), time domain reflectometry probes (TDR) and water-filled tensiometers (CT) in evaporation container 1 (EB1) that was filled with sand. Each subfigure shows a POT-TDR pair installed opposite to one another, and the nearest CT. 


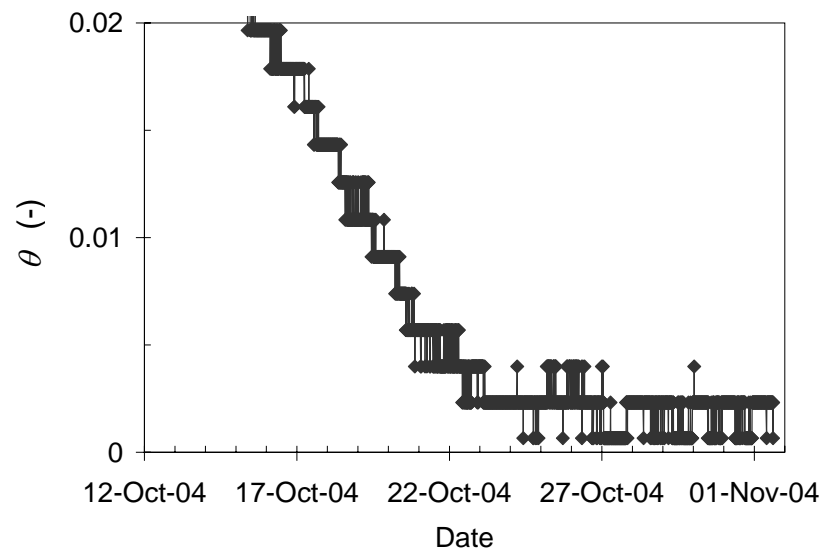

Fig. 6. Volumetric moisture content $\theta$ measurements in dry soil by one of the time domain reflectometers (TDR1) installed in evaporation container 1 (EB1).

know the reason for the sudden pressure in- and decreases observed by the POTs. The observed behavior of the POTs in Fig. 5 stays within 1\% of the POT's measurement range, and was therefore not considered problematic. Differences between sensors were small until 7 October 2004. Then, the converted potentials from TDR 1 and 2 started to deviate from the POT and CT measured potentials, while TDR 3 and 4 still followed the trend of the other instruments. CT1 cavitated on 19 October 2004 at $-0.025 \mathrm{MPa}$ and CT3 on 21 October 2004 at $-0.082 \mathrm{MPa}$. All POTs continued to function beyond the theoretical wilting point of $-1.6 \mathrm{MPa}$. The horizontal stretch immediately after cavitation represents atmospheric pressure within the polymer chamber (zero relative pressure). The negative $\psi_{m}$ recorded just before cavitation reflects subatmospheric pressures. The $\gamma-\mathrm{Al}_{2} \mathrm{O}_{3}$ membrane will remain saturated until $117 \mathrm{MPa}$, thus blocking air from entering the polymer chamber. Water can still leave the polymer chamber though, and as a result the volume of the polymer solution can become less than the chamber volume, producing negative pressure readings.

At 1 November 2004 when the evaporation container was moistened from below, all POTs regained their original pressure within 0.7 days, except POT1A that needed almost 4 days (Table 3 ). When rewetting the soil with tap water, the dried out ceramic was rewetted with water containing salts from the tap water. Subsequently, at 15 November 2004, small peaks in the measurements reflect replacement of the POTs of EB1 in a water bath with demineralized water. The salts in the ceramic then diffused out of the ceramic, leading to a pressure drop in the polymer solution. This diffusion resulted in an average pressure drop of $0.041 \mathrm{MPa}$, ranging from 0.020 to $0.052 \mathrm{MPa}$. From 22-24 November 2004 we determined the temperature response of the POTs to compare it to the temperature response before the evaporation experiment. No significant changes were found.

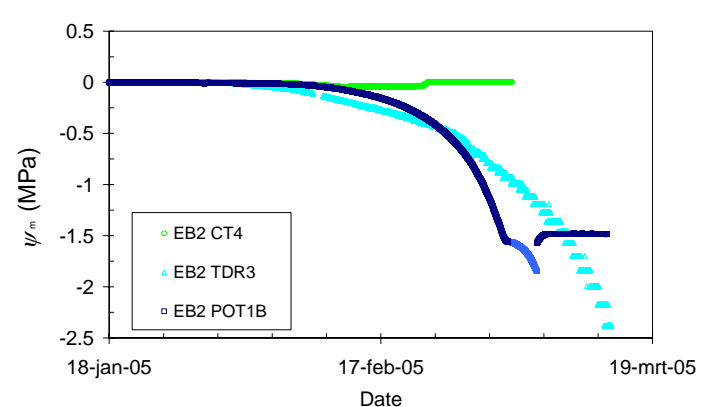

(a)

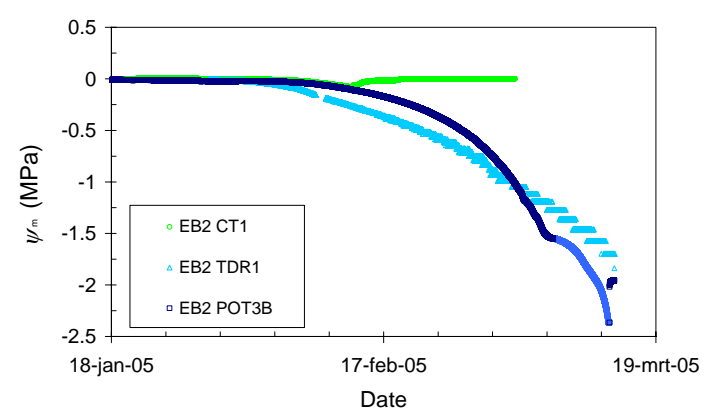

(b)

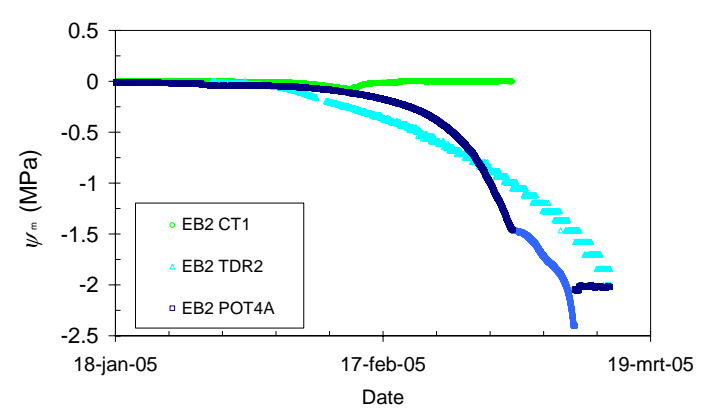

(c)

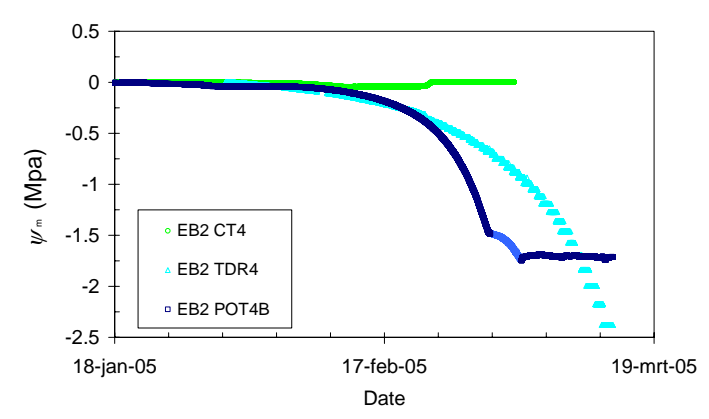

(d)

Fig. 7. Development of the matric potential $\psi_{m}$ in time measured by polymer tensiometers (POT), time domain reflectometry probes (TDR) and water-filled tensiometers (CT) in evaporation container 2 (EB2) that was filled with loam. Each sub-figure shows a POTTDR pair installed opposite to one another, and the nearest CT. 


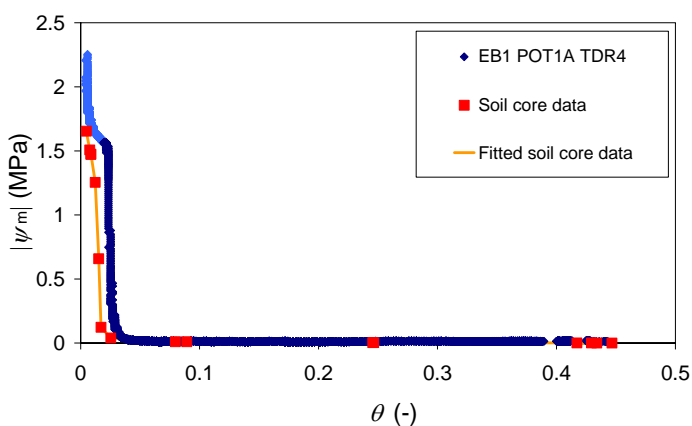

(a)

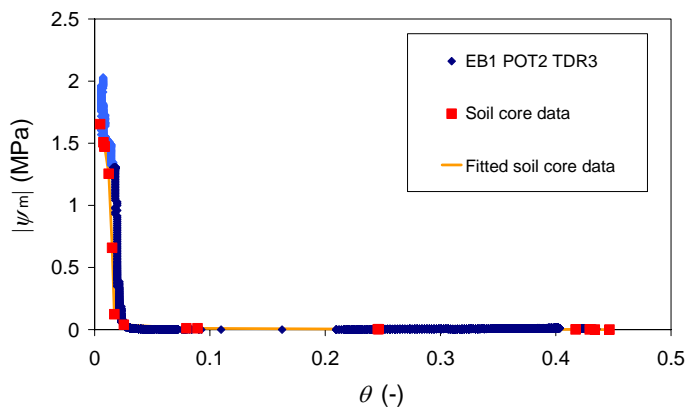

(b)

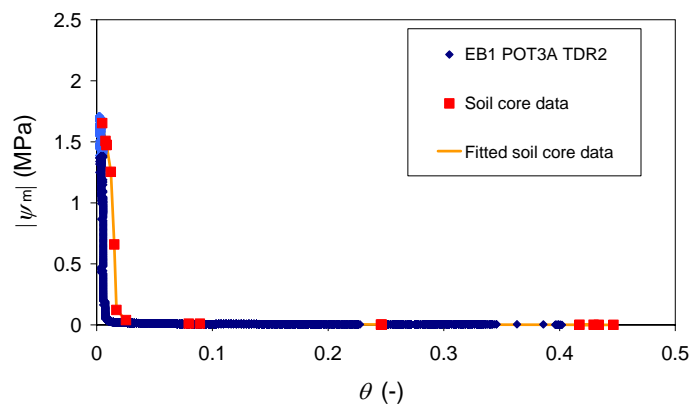

(c)

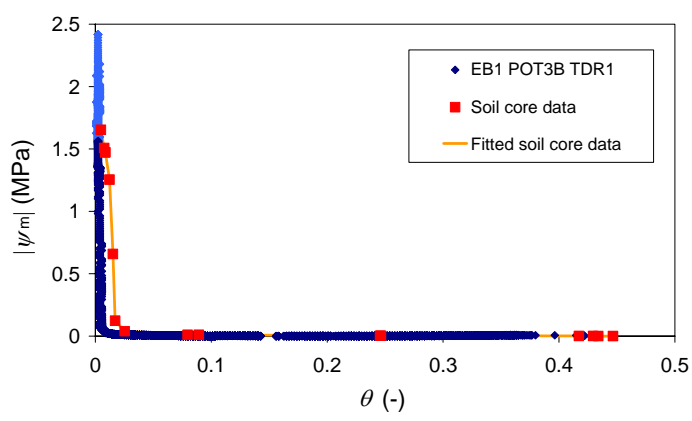

(d)

Fig. 8. Moisture retention curves of EB1 for the paired polymer tensiometers (POTs) and time domain reflectometers (TDR) together with gravimetric data from soil cores, and fitted retention curve. The minus sign of the matric pressure values $\left(\psi_{m}(\mathrm{MPa})\right)$ has been omitted.

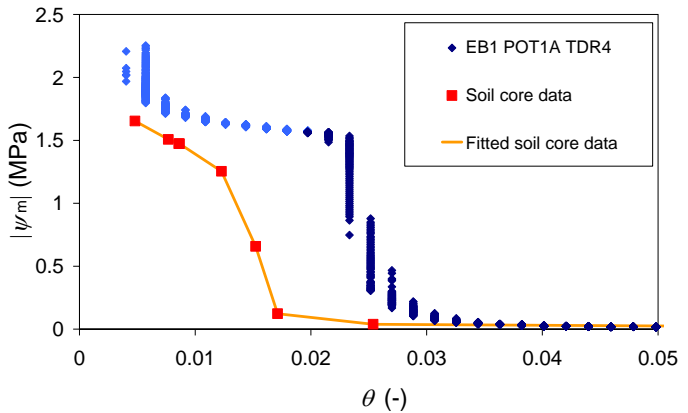

(a)

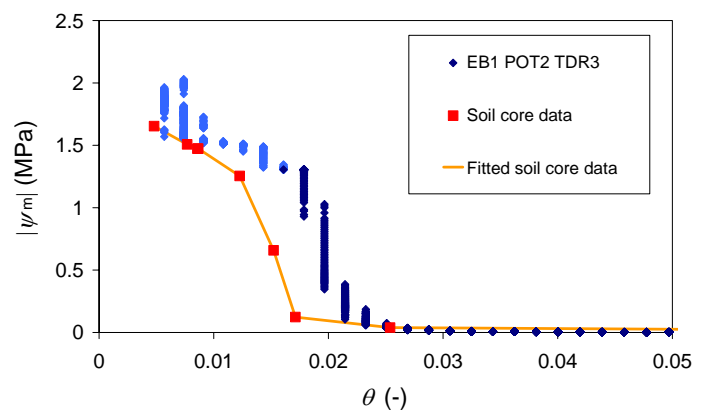

(b)

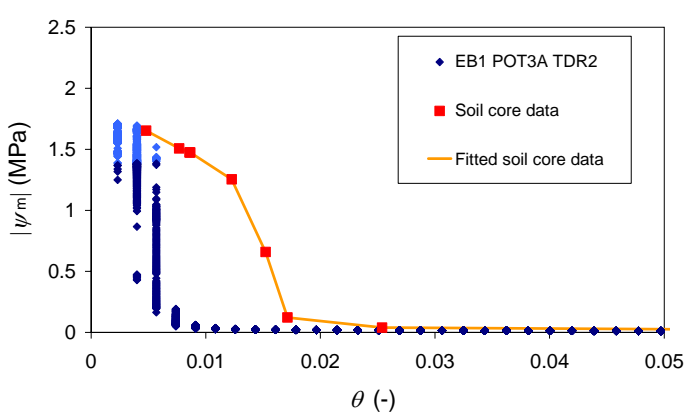

(c)

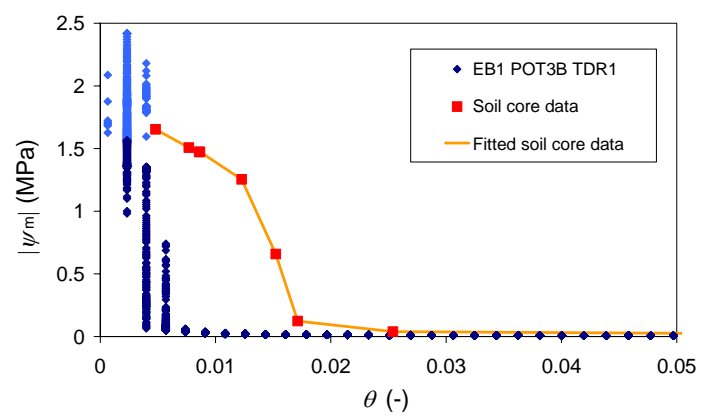

(d)

Fig. 9. Moisture retention curves (detail) of EB1 for the paired polymer tensiometers (POTs) and time domain reflectometers (TDR) together with gravimetric data from soil cores, and fitted retention curve. The minus sign of the matric pressure values $\left(\psi_{m}(\mathrm{MPa})\right)$ has been omitted. For complete curves see Fig. 8. 
In EB1, the TDRs all started to show very noisy converted $\psi_{m}$ after 20 October 2004, when the soil had dried considerably. This was due to the very low $\theta_{\text {TDR }}$ (Fig. 6). Even limited noise in $\theta_{\mathrm{TDR}}$-values is magnified in the derived $\psi_{m^{-}}$ values in the steep dry end of the moisture retention relationship.

For EB2, the comparison between POT, TDR and CT (Fig. 7) shows the same trends as in EB1; in the beginning all measurements were close, converted potentials of the TDRs started to deviate around 7 February 2004, and CT and POT data were in good agreement until the CTs cavitated; CT1 on 13 February 2005 at $-0.083 \mathrm{MPa}$, and CT4 on 15 February 2005 at $-0.050 \mathrm{MPa}$. All POTs functioned beyond wilting point. After the experiment, when we placed the POTs in the temperature controlled water bath, all POTs regained pressure within $0.7 \mathrm{~d}$ (Table 3). Comparison of the rewetting times of POT3B in the soil and the water bath indicate a faster pressure recovery in the water bath. The slower recovery in the soil probably stems from the wetting front that traveled upwards through the soil, and the available water flux at the interface between soil and ceramic. Temperature response of the POTs in EB2 was not significantly different before and after the evaporation experiment.

For both EB experiments, the POTs showed a bump that occurred at -1.3 to $-1.7 \mathrm{MPa}$ (the starting point of the bump is determined by $\mathrm{d} \pi / \mathrm{d} t=0$, with $t$ time; shown in Figs. 4, 7, $8,9,10$ and 11 by a slightly lighter color). This would seem to reflect stagnation in the decreasing $\psi_{m}$, but did not happen at equal $\pi$ for all POTs, thus suggesting a reason intrinsic to individual POTs. A possible explanation could be the air entry values of the ceramics. If the specified ceramic's air entry value is the result of averaging or random testing, the actual air entry value of an individual ceramic will deviate to some degree from the specified value. As soon as $\psi_{m}$ reaches the air entry pressure of the ceramic, the soil is wetted by a small amount of water flowing out of the ceramic, thereby temporarily reducing the gradient between the soil and the polymer chamber. From the moment the soil is wetted by water in the ceramic, the POT essentially measures the potential of the partially saturated ceramic, which deviates from $\psi_{m}$ because of the gradient that needs to be sustained to maintain the small water flux from the ceramic induced by the drying soil. Beyond the air-entry value of the ceramic the ceramic thus acts as an unsaturated porous medium. In this case, a matric potential change leads to a water flux into or out of the ceramic, and deviations may be due to a time lag in the equalization of pressure in the POT's polymer chamber.

The TDR converted $\psi_{m}$ showed some noise, but this did not explain the observed difference between the TDR and POT measurements, that was more pronounced in EB2 compared to EB1. These differences will be explained by comparing the moisture retention curves from in situ observation, soil core data, and water retention fits.

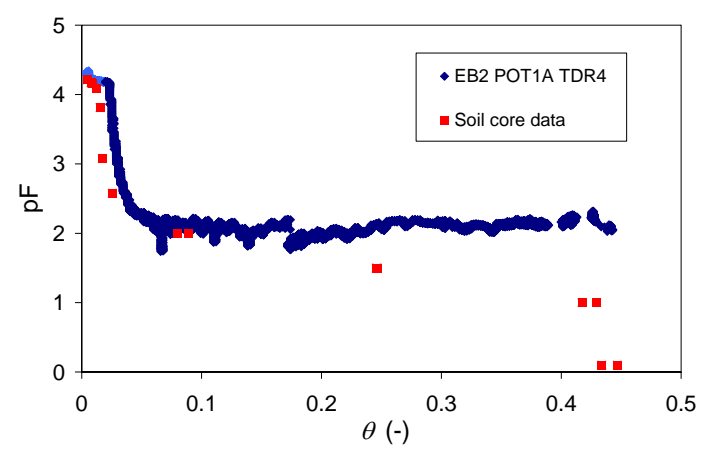

(a)

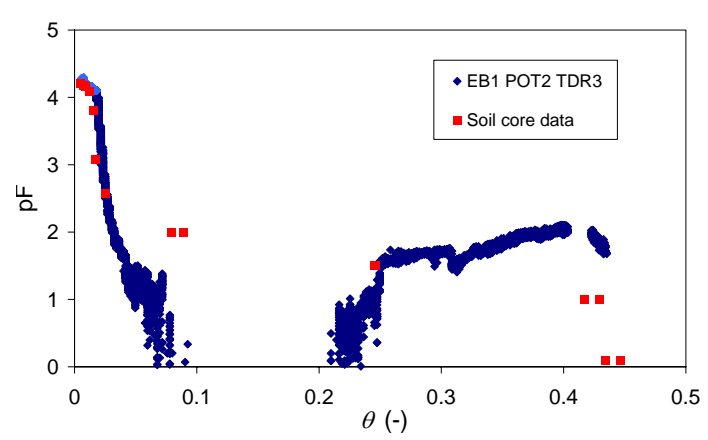

(b)

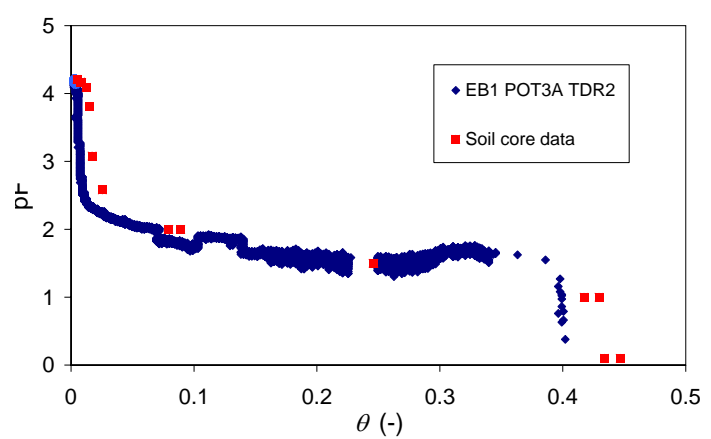

(c)

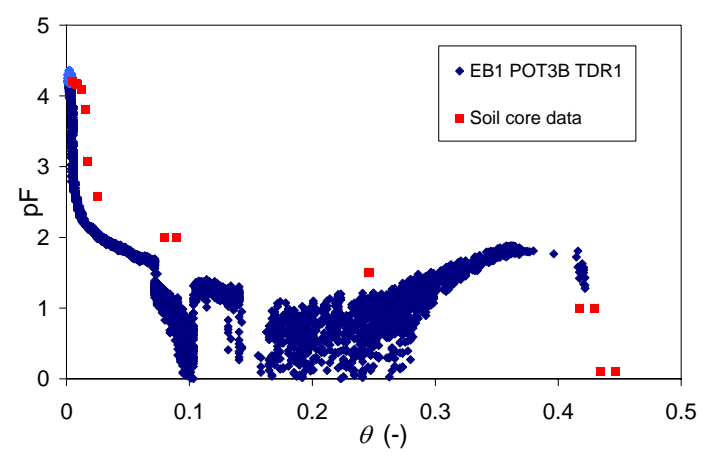

(d)

Fig. 10. $\mathrm{pF}$ curve of EB1 for the paired polymer tensiometers (POTs) and time domain reflectometers (TDR) together with gravimetric data from soil cores. 


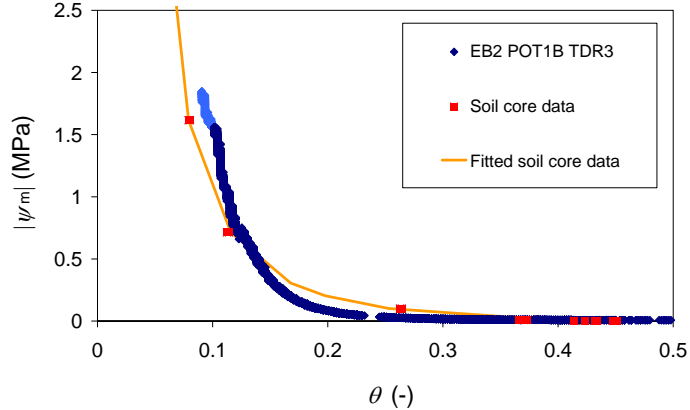

(a)

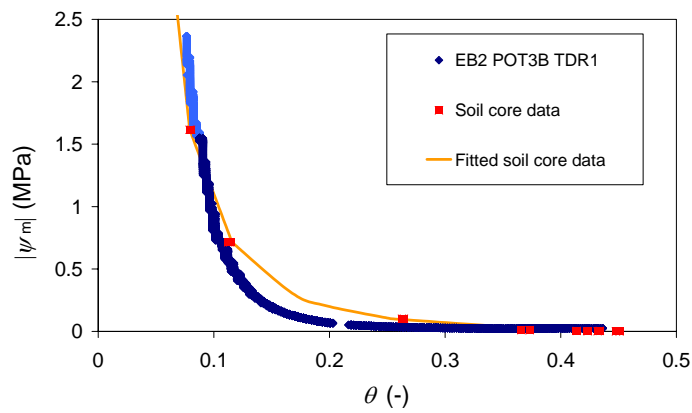

(b)

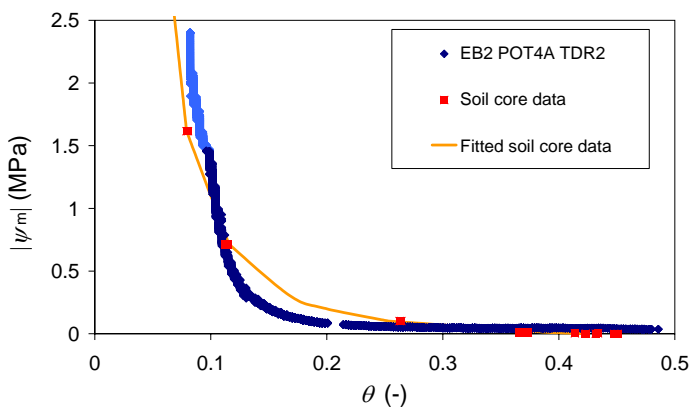

(c)

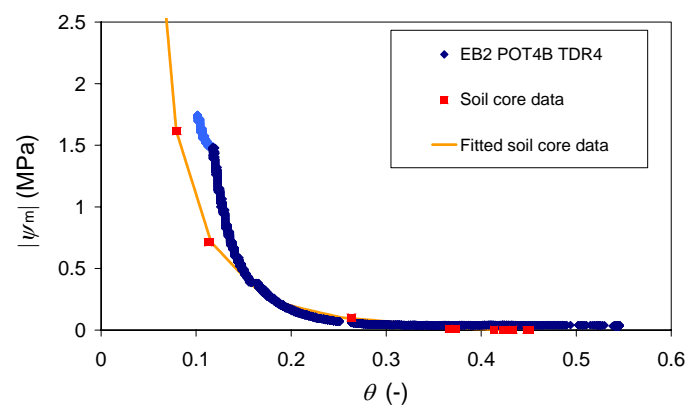

(d)

Fig. 11. Moisture retention curves of EB2 for the paired polymer tensiometers (POTs) and time domain reflectometers (TDR) together with gravimetric data from soil cores, and Van Genuchten fitted retention curve. The minus sign of the matric pressure values $\left(\psi_{m}(\mathrm{MPa})\right)$ has been omitted.

\subsection{Comparison of moisture retention curves}

We plotted retention curves of $\theta_{\mathrm{TDR}}$ and the POT-measured $\psi_{m}$ together with soil core data and fitted retention curves (Figs. 8, 9, 10, and 11). We were interested in the dry end of the moisture retention curve, and therefore mostly plotted on a linear scale instead of the more conventional log scale.

From Figs. 8, 9, 10 and 11 it can be seen that in situ and soil core data deviate slightly from each other, probably as a result of different measurement techniques. Madsen et al. (1986) and Peck and Rabbidge (1969) also observed discrepancies between pressure plate and other methods, although these authors mostly observed moisture contents that were higher in case of the pressure plate method, while we sometimes observed lower moisture contents as well. Nevertheless, despite the differences in measurement volumes and instrument location of POTs and TDRs, the in situ retention curves approximate the retention curves determined on soil core data.

With the observed and fitted retention data we can explain the observed differences between TDR converted potentials and the POT measured potentials (Figs. 4 and 7).

In Fig. 9a, b and 10a, b, the soil core data and the fit on soil core data show slightly lower pressure values than the in situ observations when $\theta$ is between 0 and 0.05 , while in Fig. 9c, d, and 10c, d, the soil core data and fit show slightly higher values than the in situ observations in the same range. This explains the deviations of the TDR converted potentials from POT measured potentials in Fig. 4, where TDR3 and 4 seem to have slightly less negative potentials from 7 October 2004, while TDR1 and 2 show the opposite. Figure 10 shows the $\mathrm{pF}$ of Fig. 8, and highlights the deviations between in situ and soil core data between $\mathrm{pF} 0$ and 2 . Slightly positive pressure data from POTs were omitted in this figure. Due to the limited signal resolution of the POTs noise can be substantial on a $\mathrm{pF}$ scale. In the experimental setup, TDR probes and the POTs were paired to maximize consistency between their readings, which enforced an increase in the distance between the POTs and the CTs. Thus, the CTs were placed in a different soil volume (surrounded by four air drains), and may have experienced a slightly different drying regime than the TDRs. Therefore, CT data were not included in Fig. 10.

For EB2, the deviations between in situ observations, soil core data and fits are more pronounced, and occur over the entire range of measured potentials (see Fig. 11). In Fig. 10b, the soil core data and fitted values indicate higher suctions than the in situ observations at a moisture content of around 0.25 , and the the fitted soil core observations and the in situ observations cross around a moisture content of 0.1-0.15. This is resembled in Fig. 7b, where the TDR converted potentials are lower than the POT and CT observations from 7 to 27 February 2005, while later on the POT and TDR converted potentials lie much closer. In Fig. 11a, c, the fitted soil core observation at $1.6 \mathrm{MPa}$ deviates as well, and similarly the TDR converted potentials show larger deviations in 
Fig. 7a, c. In Fig. 11d, the fitted soil core observation at a moisture content of about 0.25 does coincide with the in situ observations, but at $1.6 \mathrm{MPa}$ the deviation from the in situ observations is even more pronounced than in Fig. 11a-c, and this can also be observed in the TDR converted potentials in Fig. 7d.

Retention curve fits have to be interpreted carefully in the dry range of the moisture retention curve, and in combination with the limited accuracy of TDR in dry soils highlight the risk of using TDR converted potentials in that range.

\section{Conclusions}

The temperature response times of the various designs indicate an effect of polymer chamber size, and ceramic area in contact with the polymer solution. Designs that minimized polymer chamber height, while maximizing the ceramic area in contact with polymer solution had the shortest response times. For all POT designs response times to regain pressure by rewetting were remarkably shorter than reported by Bakker et al. (2007). It should be noted that the reported response times are an extreme scenario; from completely dry polymer to fully saturated. In practice, pressure recovery will generally be much faster.

POTs with ceramic cones have enhanced soil contact compared to POTs with flat ceramics; we never observed poor soil contact. We compared four designs by testing them in soil, and the results showed similar responses. A preferred design therefore mostly depends on the maximization of the ceramic membrane's surface in contact with the polymer solution, and the polymer chamber's depth (Bakker et al., 2007). To prevent pressure differences as a result of different solute concentrations in soil water and water bath we recommend the use of similar solutions before, during and after soil experiments.

In situ moisture retention curves approximated the retention curves from soil cores. Although in situ moisture retention curves will never exceed the upper measurement limit of POTs, pairing POT and TDR data will give a unique opportunity to study the temporal dynamics of moisture retention curves in field soils. Furthermore, POTs can be applied for determination of unsaturated soil hydraulic properties over a larger continuous range, like the estimation of the unsaturated hydraulic conductivity in either conventional (Arya, 2002) or novel (Schneider et al., 2006) experimental setups.

A detailed analysis of POT-measured matric potentials, TDR-measured moisture contents, and the fitted retention curve revealed the risks associated with converting soil moisture readings in dry soils to matric potentials.

Acknowledgements. This research was supported by the Technology Foundation STW, applied science division of NWO and the technology program of the Ministry of Economic Affairs.

Edited by: W. Durner

\section{References}

Agus, S. S. and Schanz, T.: Comparison of four methods for measuring total suction, Vadose Zone J., 4, 1087-1095, 2005.

Alami-Younssi, S., Larbot, A., Persin, M., Sarrazin, J., and Cot, L.: Rejection of mineral salts on a gamma alumina nanofiltration membrane, application to environmental process, J. Membr. Sci., 102, 123-129, 1995.

Andraski, B. J. and Scanlon, B. R.: Thermocouple psychrometry, in: Methods of Soil Analysis. Part 4., edited by: Dane, J. H. and Topp, G. C., SSSA Book Ser. 5. SSSA, Madison, WI, p. 609642, 2002.

Arya, L. M.: Wind and hot-air methods, in: Methods of soil analysis Part 4 Physical Methods, edited by: Dane, J. H., and Topp, G. C., Soil Science Society of America Book Series No 5, Madison, WI, USA, 2002.

Bakker, G., van der Ploeg, M. J., de Rooij, G. H., Hoogendam, C. W., Gooren, H. P. A., Huiskes, C., Koopal, L. K., and Kruidhof, H.: New polymer tensiometers: Measuring matric pressures down to the wilting point, Vadose Zone J., 6, 196-202, 2007.

Biesheuvel, P. M., Raangs, R., and Verweij, H.: Response of the osmotic tensiometer to varying temperatures: modeling and experimental evaluation, Soil Sci. Soc. Am. J., 63, 1571-1579, 1999.

Bocking, K. A. and Fredlund, D. G.: Use of the osmotic tensiometer to measure negative pore water pressure, Geotech. Test. J., 2(1), 3-10, 1979.

Campbell, G. S.: Soil water potential measurement: An overview, Irrig. Sci., 9, 265-273, 1988.

Campbell, G. S. and Gee, G. W.: Water potential: in: Miscellaneous methods, edited by: Klute, A., Methods of soil analysis. Part 1. 2nd ed., Agron. Monogr., 9. ASA and SSSA, Madison, WI, 619633, 1986.

Caulfield, M. J., Hao, X., Qiao, G. G., and Solomon, D. H.: Degradation on polyacrylamides. Part I. Linear polyacrylamide, Polymer, 44, 1331-1337, 2003.

Dane, J. H. and Hopmans, J. W.: Water retention and storage, p. 671-673, in: Methods of Soil Analysis. Part 4. SSSA Book Ser. 5. SSSA, edited by: Dane, J. H. and Topp, G. C., Madison, WI, 2002.

Davidson, R. L.: Handbook of water-soluble gums and resins. McGraw-Hill, Inc, New York, 16-2, 1980.

De Vos, R. M. and Verweij, H.: Improved performance of silica membranes for gas separation, J. Membrane Sci., 143, 37-51, 1998.

Dirksen, C.: Soil physics measurements, GeoEcology paperback, Catena Verlag, Germany, 18-20, 1999.

Ferré, P. A., Knight, J. H., Rudolph, D. L., and Kachanoski, R. G.: The sample areas of conventional and alternative time domain reflectometry probes, Water Resour. Res., 34, 2971-2979, 1998.

Ferré, P. A. and Topp, G. C.: Time Domain Refelctometry, in: Methods of Soil Analysis. Part 4. SSSA Book Ser. 5. SSSA, edited by: Dane, J. H. and Topp, G. C., Madison, WI, 2002.

Grossman, R. B. and Reinsch, T. G.: Bulk density and linear extensibility. in: Methods of Soil Analysis. Part 4. SSSA Book Ser. 5. SSSA, edited by: Dane, J. H., and Topp, G. C., Madison, WI, 2002.

Guan, Y. and Fredlund, D. G.: Use of tensile strength of water for the direct measurement of high soil suction, Can Geotech. J., 34, 604-614, 1997. 
Huisman, J. A., Sperl, C., Bouten, W., and Verstraten, J. M.: Soil water content measurements at different scales: accuracy of time domain reflectometry and ground-penetrating radar, J. Hydrol., 245, 48-58, 2001.

Madsen, H. B., Jensen, C. R., and Boysen, T.: A comparison of the thermocouple psychrometer and the pressure plate methods for determination of soil water characteristic curves, J. Soil Sci., 37, 357-362, 1986.

Miller, E. E. and Salehzadeh, A.: Stripper for bubble-free tensiometry, Soil Sci. Soc. Am. J., 57, 1470-1473, 1993.

Molyneux, P.: Water-soluble synthetic polymers: Properties and behavior, Vol. 1., CRC Press, Inc, FL, 11, 1983.

Noborio, K., Horton, R., and Tan, C. S.: Time domain reflectometry probe for simulteneous measurement of soil matric potential and water content, Soil Sci. Soc. Am. J., 63, 1500-1505, 1999.

Or, D.: Who invented the tensiometer?, Soil Sci. Soc. Am. J., 65, $1-3,2001$.

Or, D. and Wraith, J. M.: A new soil matric potential sensor based on time domain reflectometry, Water Resour. Res., 35 (11), 3399-3407, 1999.

Peck, A. J. and Rabbidge, R. M.: Soil-water potential: Direct measurement by a new technique, Science, 151, 1385-1386, 1966.

Peck, A. J. and Rabbidge, R. M.: Design and performance of an osmotic tensiometer for measuring capillary potential, Soil Sci. Soc. Am. Proc., 33, 196-202, 1969.

Reece, C. F.: Evaluation of a line heat dissipation sensor for measuring soil matric potential, Soil Sci. Soc. Am. J., 60, 1022-1028, 1996.

Ridley, A. M. and Burland, J. B.: A new instrument for the measurement of soil moisture suction, Geotechnique, 43, 321-324, 1993.
Ridley, A. M. and Burland, J. B.: Use of tensile strength of water for the direct measurement of high soil suction: Discussion. Can. Geotech. J., 36, 178-180, 1999.

Romano, N., Hopmans, J. W., and Dane, J. H.: Suction table, in: Methods of Soil Analysis. Part 4. SSSA Book Ser. 5. SSSA, edited by: Dane, J. H. and Topp, G. C., Madison, WI, USA, 2002.

Schindler, U., Durner, W., von Unold, G., and Müller, L.: Evaporation Method for Measuring Unsaturated Hydraulic Properties of Soils: Extending the Measurement Range, Soil Sci. Soc. Am. J., 74, 1071-1083, 2010.

Schneider, K., Ippisch, O., and Roth, K.: Novel evaporation experiment to determine soil hydraulic properties, Hydrol. Earth Syst. Sci., 10, 817-827, doi:10.5194/hess-10-817-2006, 2006.

Tamari, S., Gaudu, J.-C., and Simonneu, T.: Tensiometric measurement and metastable state of water under tension, Soil Sci., 156, 149-155, 1993.

Tarantino, A. and Mongiovì, L.: Experimental procedures and cavitation mechanisms in tensiometer measurements, Geotechnical and Geological Engineering, 19, 189-210, 2001.

Topp, G. and Ferré, P. A.: Water content, General information, in: Methods of Soil Analysis. Part 4. SSSA Book Ser. 5. SSSA, edited by: Dane, J. H. and Topp, G. C., Madison, WI, USA, 2002.

van Genuchten, M. Th.: A closed-form equation for predicting the hydraulic conductivity of unsaturated soils, Soil Sci. Soc. Am. J., 44, 892-898, 1980.

Young, M. H. and Sisson, J. B.: Tensiometry, in: Methods of Soil Analysis. Part 4. SSSA Book Ser. 5. SSSA, edited by: Dane, J. H. and Topp, G. C., Madison, WI, 2002. 